\title{
Review
}

Pharmacology

\section{The Clinical Use of Cetirizine in the Treatment of Allergic Rhinitis}

\author{
Luo Zhang $^{\text {a }}$ Lei Cheng ${ }^{b}$ Jianguo Hong ${ }^{c}$ \\ ${ }^{a}$ Department of Otolaryngology, Head and Neck Surgery, Beijing Tongren Hospital, Capital Medical University, \\ Beijing, ${ }^{b}$ Department of Otorhinolaryngology, First Affiliated Hospital, Nanjing Medical University, Nanjing, and \\ 'Department of Pediatrics, Shanghai First People's Hospital, Shanghai Jiaotong University, Shanghai, China
}

\section{Key Words}

Allergic rhinitis · Benchmark · Cetirizine - Efficacy ·

$\mathrm{H}_{1}$ antihistamines · Pharmacodynamics · Pharmacokinetics . Quality of life · Safety · Somnolence

\begin{abstract}
Background: Cetirizine is among the first second-generation $\mathrm{H}_{1}$ antihistamines (SGAHs) developed to provide selective $\mathrm{H}_{1}$ receptor inhibition without central nervous system depression. Objective: The aim of this review is to summarize the amount of data collected over 25 years of clinical use of cetirizine and compare this with data available for other SGAHs in the management of patients with allergic rhinitis (AR). Methods: A comprehensive literature search for publications relating to cetirizine was performed using the Pubmed database, and relevant papers published in English were selected for detailed review. Results: Compared with the majority of other SGAHs, cetirizine was generally shown to have a more favourable pharmacological profile, to be well tolerated, be at least equally or more efficacious in attenuating/inhibiting nasal and ocular symptoms and to improve the quality of life in AR patients. The majority of clinical trials investigating the effect of SGAHs in AR patients further indicated that cetirizine was often employed as the main comparator active drug. Conclusion: Based on the evidence that cetirizine is a commonly employed active comparator
\end{abstract}

\section{KARGER}

E-Mail karger@karger.com

www.karger.com/pha drug in AR, it is tempting to suggest that cetirizine may be a suitable benchmark in the development of novel pharmacotherapies for AR.

Copyright $\odot 2013$ S. Karger AG, Basel

\section{Introduction}

Allergic rhinitis (AR) is a common chronic respiratory disorder characterized by nasal symptoms including sneezing, rhinorrhoea, nasal congestion and nasal itching, often accompanied by ocular symptoms including itching/redness and/or lacrimation in $60-70 \%$ of patients $[1,2]$. Although the symptoms of AR are not life threatening, they are usually bothersome, adversely affect work and quality of life of affected individuals [1-4], and have the potential to cause physical, mental and emotional complications in children and adolescents [5-7]. The prevalence of AR has increased progressively over the last few decades and varies greatly from region to region and country to country among particularly the developing nations [8]. For example, an across-sectional population-based telephone survey of 38,203 individuals in 11 major cities across China demonstrated that the self-reported prevalence of AR varied between $8.7 \%$ in Beijing in North China to $24.1 \%$ in Urumqi in North-West China, with intermediate AR prevalences of $13.6 \%$ in Shanghai in East China, $14.1 \%$ in 
Guangzhou in Central China and $19.3 \%$ in Wuhan in South China [9]. Furthermore, there is evidence that affluence and the accompanying improvements in education and living standards particularly in some African countries, China, Hong Kong, Taiwan, and several Middle East countries have coincided with a marked increase in the prevalence of AR in these countries [8]. There is also a growing consensus that allergies are becoming more persistent and complex and that this is likely to be a consequence of perennial exposure to indoor allergens and increased exposure to multiple cross-reacting traditional and non-traditional sensitizing agents, resulting from changes in indoor environment/lifestyle/affluence [8-11].

Treatment of AR and conjunctivitis in adults and children is currently recommended with oral second-generation $\mathrm{H}_{1}$ antihistamines (SGAHs) and intranasal steroids, with SGAHs used as first-line medications for mild to moderately severe disease [12-14]. The updated evidence-based ARIA (Allergic Rhinitis and Its Impact on Asthma) guidelines have further indicated that of all the drugs used for the treatment of 'persistent' AR (PER), the level of evidence is most compelling for the oral SGAHs [12], thus confirming their choice as the preferred firstline medications for treatment of this condition.

The development of $\mathrm{H}_{1}$ antihistamines, following the discovery of histamine, and their role in the treatment of allergy and anaphylaxis have been well documented [15, 16]. Although the first-generation $\mathrm{H}_{1}$ antihistamines were developed and widely used clinically from the mid1940s to the late 1970s; a comparably lower efficacy and association with particularly sedative and anticholinergic side effects have restricted their usefulness and subsequently led to the development of the more efficacious and safer SGAHs $[15,16]$. Indeed, there is evidence that the first-generation $\mathrm{H}_{1}$ antihistamines may actually lead to central excitation, restlessness, insomnia, or seizures in some patients $[17,18]$. Thus, it is now recommended that the first-generation $\mathrm{H}_{1}$ antihistamines should neither be available over the counter as prescription-free drugs for self-medication of allergic or other diseases [17] nor be used for treatment of AR [12]. Similarly, clinical experience with astemizole and terfenadine, which were among the first SGAHs to be developed to provide selective $\mathrm{H}_{1}$ receptor inhibition without central nervous system depression, has indicated that these agents are associated with the potential risk of cardiotoxicity and have therefore been withdrawn from several markets [19]. In contrast, cetirizine, which was also among the first SGAHs made available for patients, is still commonly used worldwide for the treatment of AR and urticaria.

Cetirizine in Allergic Rhinitis
There is a plethora of evidence on cetirizine, a pharmacologically active carboxylated metabolite of hydroxyzine. A Pubmed search using 'cetirizine' as the key word revealed some 1,200 publications, more than 400 of which were based on data from clinical trials, and more than 200 being based on comparative studies (Pubmed accessed February 26, 2013). The aim of this review was thus to summarize the vast amount of data collected over 25 years for clinical use of cetirizine and compare this with data available for other SGAHs.

\section{Pharmacological Characteristics of Cetirizine}

Cetirizine hydrochloride [ZyrtecC; chemical name: (+/-)-(2-[4-([4-chlorophenyl] phenylmethyl)-1-piperazinyl] ethoxy)acetic acid dihydrochloride] is a racemic mixture composed of equal amounts of two enantiomers, $\mathrm{R}$-levocetirizine and S-dextrocetirizine, which do not undergo interconversion and therefore maintain configuration stability in the body [20]. Cetirizine has been shown to have highly favourable pharmacological properties. In particular, cetirizine is a zwitterion, with high binding to mainly serum albumin and low apparent volume of distribution, as well as low brain uptake [21], which are indicative of a low affinity for lean tissues such as the myocardium (thus low cardiotoxicity) and low/lack of sedative effects, respectively. Tillement [22] has demonstrated that cetirizine has among the lowest apparent volume of distribution of the majority of SGAHs, which is compatible with the therapeutic goal of interacting with the target receptors at effective concentrations, while avoiding organs where the drug is ineffective or toxic (fig. 1). Cetirizine has also been shown to be absorbed extensively and rapidly from the gut [23], leading to high bio-availability and rapid onset of action of the drug [24], and unlike many other SGAHs cetirizine does not undergo hepatic metabolism to any appreciable extent, but is excreted mostly unchanged in the urine, equally well in both healthy volunteers and patients with chronic liver disease [25]. The lack of hepatic metabolism demonstrates a low potential for drug-drug interactions, which avoids any exaggerated pharmacological or toxicological effects with drugs that are subject to metabolism by $\mathrm{P} 450$ enzymes and to transmembrane transport [26]. With an elimination half-life of around $10.5 \mathrm{~h}$ in healthy volunteers [27], cetirizine is used as once daily dosage for the treatment of AR symptoms. Similarly, $\mathrm{H}_{1}$ receptor binding studies have demonstrated that compared with many other commonly used 2nd-generation $\mathrm{H}_{1}$ antihistamines, cetirizine 
Fig. 1. Relationship between potential sites of action and volume of distribution of common $\mathrm{H}_{1}$ antagonists (adapted from Tillement [22]). Volume of distribution values cited from Gillman et al. [91] and Chu et al. [92].

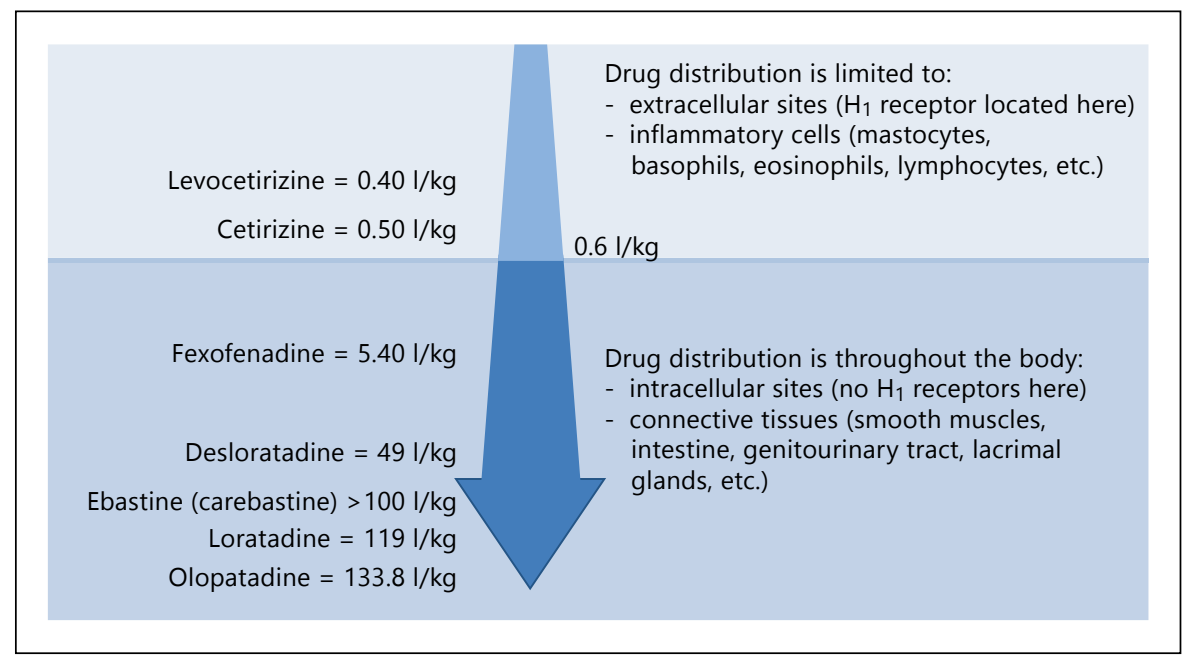

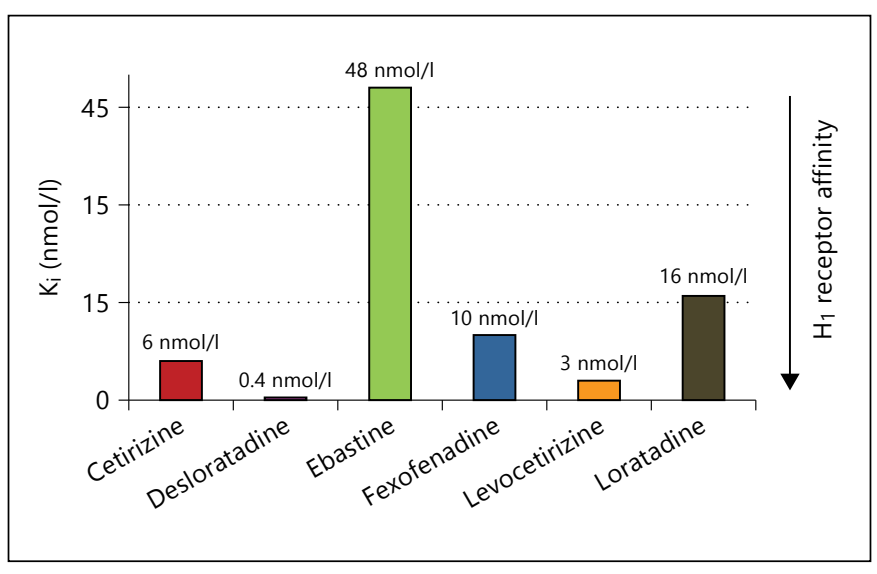

Fig. 2. Binding affinity of histamine antagonists for human histamine $\mathrm{H}_{1}$ receptors (adapted from Gillard et al. [28]). $\mathrm{K}_{\mathrm{i}}=$ Inhibition constant, the lower the amount of a drug needed to inhibit the $\mathrm{H}_{1}$ receptor, the higher its affinity.

Table 1. $\mathrm{H}_{1}$ receptor selectivity of major SGAHs: the higher the ratio, the higher the selectivity for the $\mathrm{H}_{1}$ receptor (data from Gillard et al. [28])

\begin{tabular}{llllll}
\hline Antihistamine & \multicolumn{4}{l}{$\begin{array}{l}\text { Binding selectivity ratio for the histamine }\left(\mathrm{H}_{1}\right) \\
\text { receptors versus muscarinic }\end{array}$} \\
\cline { 2 - 6 } & $\left.\mathrm{H}_{1} / \mathrm{M}_{1}\right)$ & $\mathrm{H}_{1} / \mathrm{M}_{2}$ & $\mathrm{H}_{1} / \mathrm{M}_{3}$ & $\mathrm{H}_{1} / \mathrm{M}_{4}$ & $\mathrm{H}_{1} / \mathrm{M}_{5}$ \\
\hline Cetirizine & $>25,000$ & $\sim 100,000$ & $\sim 50,000$ & $\sim 20,000$ & $>75,000$ \\
Desloratadine & $\sim 50$ & $>50$ & $\sim 100$ & $\sim 50$ & $\sim 125$ \\
Fexofenadine & $>10,000$ & $>10,000$ & $>10,000$ & $>10,000$ & $>10,000$ \\
Levocetirizine & $>25,000$ & $>75,000$ & $\sim 50,000$ & $>25,000$ & $\sim 100,000$ \\
Loratadine & $\sim 100$ & $>350$ & $\sim 100$ & $\sim 100$ & $>500$ \\
\hline
\end{tabular}

16 has a relatively higher and more favourable affinity and selectivity for $\mathrm{H}_{1}$ receptors (table 1; fig. 2), which confers a more potent, faster onset and longer duration of action [28]. Studies investigating the anti-inflammatory/anti-allergic effects of cetirizine have indicated that it may exhibit anti-inflammatory properties independent of its $\mathrm{H}_{1}$ effects [29].

\section{Pharmacological Studies of Cetirizine in Patients with $A R$}

Several studies have investigated the pharmacological effects of cetirizine in patients with AR. An early study by Watson et al. [30] evaluated the pharmacokinetic and pharmacodynamic properties of cetirizine 5 or $10 \mathrm{mg}$ daily for 5 weeks in children with seasonal AR (SAR), using a randomized, double-blind, and parallel-group study design. The authors demonstrated that cetirizine was absorbed rapidly at both the 5- and 10-mg doses which were similarly and significantly effective in suppressing the mean histamine-induced wheal and flares, $1-24 \mathrm{~h}$ after the first dose, an effect maintained over the entire study period. Similarly, the symptoms and signs of AR were suppressed throughout the study, with no patient reporting sedation, dry mouth, or any other adverse effect at either dose of cetirizine investigated.

Several studies have evaluated the anti-inflammatory properties of cetirizine in children and adults with seasonal or perennial AR [31-35]. Ciprandi et al. [31] demonstrated that children treated with cetirizine $5 \mathrm{mg} /$ day for 4 weeks during the pollen season exhibited significantly reduced clinical symptoms $(\mathrm{p}<0.01)$, as well as reduced inflammatory cell infiltrate $(p<0.03)$, 
Fig. 3. Inhibition of the skin wheal formation in healthy volunteers following the intradermal injection of histamine, and after prior oral administration of different antihistamines (adapted from Grant et al. [37]). The inhibition of the flare formation was similar (not shown).

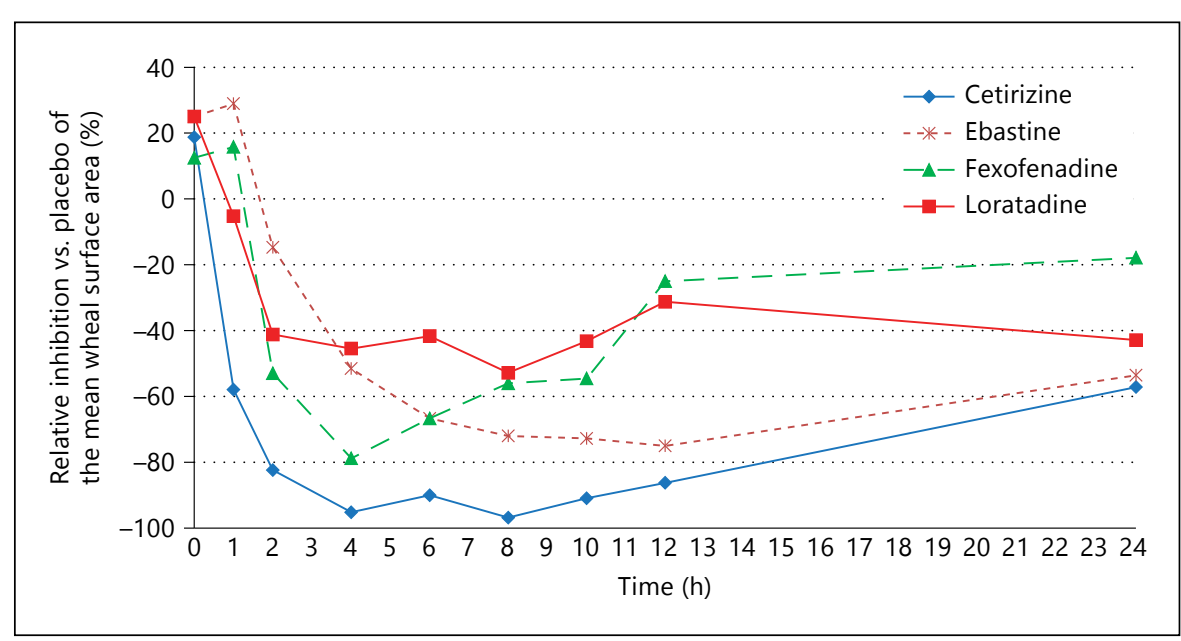

intercellular adhesion molecule 1 (ICAM-1) expression on epithelial cells $(\mathrm{p}<0.05)$, and soluble ICAM-1 ( $<<$ $0.05)$ and eosinophil cationic protein $(\mathrm{p}<0.05)$ in nasal lavage, compared with placebo. Moreover, there was a significant correlation between symptom improvement and cellular infiltration and ICAM-1 expression, of which the correlation between symptom improvement and ICAM-1 was particularly strong. Similarly, investigations of the effect of treatment with cetirizine $5 \mathrm{mg} /$ day for 2 weeks on inflammation in the nasal mucosa of children suffering from perennial AR (PAR) have demonstrated cetirizine to be significantly more effective than placebo in reducing interleukin $4(\mathrm{p}<0.01)$, interleukin $8(\mathrm{p}=0.01)$, neutrophils and eosinophil numbers $(\mathrm{p}<0.01)$, and ICAM-1 expression on epithelial cells $(\mathrm{p}<0.02)$ in this patient cohort $[32,33]$. In fact, there is evidence that continuous treatment with cetirizine is more effective than on-demand treatment in achieving significantly greater inflammatory and clinical control in AR patients $[34,35]$. One recent study evaluated the effects of a 2 -year course of subcutaneous specific immunotherapy with continuous oral cetirizine $10 \mathrm{mg} /$ day on nasal inflammation in patients with house dust mite-induced severe PER, and indicated that although both treatment regimens significantly reduced eosinophil infiltration and epithelial ICAM1 expression from baseline levels over the course of treatment, treatment with cetirizine appeared to be more effective in controlling inflammation [35] while immunotherapy appeared to be more effective in controlling epithelial disruption. In another study, treatment for 1 week with cetirizine was found to reduce antigen-induced substance $P$, but not histamine levels in patients with PAR, suggesting that cetirizine may reduce nasal neurogenic inflammation by modulating the release of substance P in AR [36].

\section{Studies Comparing the Pharmacological Effects of}

\section{Cetirizine with Other SGAHs}

The pharmacological effects of the majority of SGAHs have been extensively compared with those of cetirizine in both healthy volunteers and patients with AR in several double-blind, crossover, and multiple- and singledose studies, with particular emphasis on inhibition of histamine-induced skin wheal and flare reactions. In one early study, Grant et al. [37] evaluated the effect of 2 weeks' treatment with cetirizine $10 \mathrm{mg}$, ebastine $10 \mathrm{mg}$, epinastine $20 \mathrm{mg}$, fexofenadine $60 \mathrm{mg}$, loratadine $10 \mathrm{mg}$, terfenadine $60 \mathrm{mg}$, or placebo on histamine-induced skin wheal and flare reactions in healthy male volunteers, over a period of $24 \mathrm{~h}$. The authors demonstrated that although epinastine had the fastest onset of action, as indicated by inhibition of both the wheal and flare reactions after $30 \mathrm{~min}$, the overall inhibition of both the wheal and flare responses produced by cetirizine was significantly superior to the other treatments (fig. 3); with the rank order for area under the curve ( $0-24 \mathrm{~h}$ ) being cetirizine $>$ epinastine $>$ terfenadine $>$ ebastine $>$ fexofenadine $>$ loratadine $>$ placebo. The superiority of single or multiple doses of cetirizine $10 \mathrm{mg}$ over therapeutic doses of acrivastine, astemizole, chlorphenamine (chlorpheniramine), ebastine, epinastine, fexofenadine, loratadine, mizolastine, oxatomide, and terfenadine in inhibiting histamineinduced skin wheal and flare reactions in atopic and nonatopic subjects has been confirmed by several other studies [38]. Similarly, more recent studies investigating the 
suppression of histamine-induced skin reactivity by the more recently developed members of this drug class have indicated the activity of cetirizine $10 \mathrm{mg}$ to be greater or equal to that of bepotastine [39], bilastine [40], desloratadine [41], levocetirizine [42], and olopatadine [39].

\section{Clinical Trials of Cetirizine in AR}

Several well-controlled trials have compared the efficacy of cetirizine with placebo and/or other $\mathrm{H}_{1}$ antihistamines in adults and children with SAR and PAR/PER [43-80]. The majority of these trials have been conducted as double-blind, randomized, placebo-controlled, parallel-group studies in large groups of patients recruited from a single or multiple centres. The fundamental inclusion criterion for all studies was the requirement for SAR or PAR/PER patients to have documented histories of allergy to seasonal (pollen/tree) or perennial (house dust mites, cockroach, animal dander or mould) allergens, respectively, confirmed by positive skin prick responses and/or radio-allergosorbent tests to specific sensitizing allergens. The patients were additionally required to demonstrate minimum total symptom severity scores (expressed as a composite of specific individual symptoms), assessed subjectively by rating individual nasal and ocular symptom severity on increasing severity scales of 0 (i.e. no symptoms) to up to 10 points (i.e. severe/very severe symptoms). Although most of the studies in SAR patients were generally conducted during specified pollen seasons, some studies investigated the effects of therapy in specially built exposure chambers, which allowed investigation of controlled pollen allergen-induced symptoms in the absence of naturally occurring confounding factors such as variable airborne pollen levels, multiple pollen/non-pollen airborne allergens, air pollutants, and variable geographic/climatic conditions [59-64].

\section{Studies Comparing Cetirizine with Placebo in SAR and PAR/PER Patients}

Several studies have compared the efficacy of cetirizine with that of placebo in patients suffering from SAR [4350] or PAR/PER [51-54]. Studies in adult patients have mostly investigated the effect of treatment with cetirizine $10 \mathrm{mg}$ once daily on the reduction of total symptom scores by the end of treatment as the main efficacy measure, and have demonstrated that cetirizine significantly decreased total and individual symptom severities compared with placebo $[43,44,49,50]$. One large multicentre study comprising 415 symptomatic SAR patients with a pretreatment total symptom severity score (for sneezing, rhinorrhoea, ocular pruritus, nasal pruritus, palatal pruritus, watering of the eyes, and redness of the eyes) of $\geq 6$ investigated the dose-dependent effect of cetirizine 5, 10, or $20 \mathrm{mg}$ once daily for 1 week, during the late summer and early fall [44]. The authors demonstrated that all doses of cetirizine were significantly more effective than placebo in reducing total daily symptom scores over the 7 days of treatment ( 5.6 for cetirizine $5 \mathrm{mg}, 5.4$ for cetirizine $10 \mathrm{mg}$ and 4.6 for cetirizine $20 \mathrm{mg}$ vs. 7.7 for placebo; $\mathrm{p}<0.05$ for all vs. placebo), with cetirizine $20 \mathrm{mg}$ demonstrating a significantly greater reduction in symptom severity compared to cetirizine $5 \mathrm{mg}(\mathrm{p}<0.05)$ [44]. An investigators' global assessment of patients at the end of the treatment period additionally indicated significantly greater numbers of patients to be treated effectively and equally with all doses of cetirizine compared to placebo (72.7\% with cetirizine $5 \mathrm{mg}, 79.3 \%$ with cetirizine $10 \mathrm{mg}$ and $76.5 \%$ with cetirizine $20 \mathrm{mg}$ vs. $52.9 \%$ with placebo; $\mathrm{p}<0.05$ for all vs. placebo). Two studies have investigated the effects of cetirizine $10 \mathrm{mg}$ on the health-related quality of life in SAR patients, using the Rhinoconjunctivitis Quality of Life Questionnaire (RQLQ) [49, 50]. Murray et al. [49] investigated a cohort of 862 symptomatic patients during the fall allergy season and demonstrated that treatment with cetirizine $10 \mathrm{mg}$ for 2 weeks resulted in significantly greater improvements in mean overall and individual domain RQLQ scores compared with placebo (change in overall score of -1.3 for cetirizine $10 \mathrm{mg}$ vs. -0.9 for placebo; $p<0.001)$. Furthermore, the improvements in scores for activities, sleep, practical problems, and eye problems were clinically relevant, as indicated by the minimally important difference criterion of $\geq 0.5$ points of reduction from baseline, and improvements from baseline in overall RQLQ and total symptom severity complex (TSSC; a composite of 6 individual rhinoconjunctivitis symptom scores for sneezing, runny nose, itchy nose, itchy eyes, watery eyes, and postnasal drip) scores at the end of treatment were significantly correlated ( $\mathrm{r}=0.73 ; \mathrm{p}<0.001$ for overall RQLQ and TSSC scores). Similarly, assessment of the effect of treatment on work/school productivity and activity impairment (WPAI), using the allergy-specific WPAI (WPAI-AS) questionnaire, indicated that apart from work hours and classroom hours missed domains, cetirizine $10 \mathrm{mg}$ resulted in significantly greater improvements in all WPAI-AS domain scores compared to placebo, with particularly the overall work impairment and classroom impairment scores being decreased from baseline by 13.5 and $19.4 \%$, respectively, in subjects treated with cetirizine $10 \mathrm{mg}$
18

Pharmacology 2013;92:14-25 DOI: $10.1159 / 000351843$
Zhang/Cheng/Hong 
compared with 5.9 and $4.9 \%$, respectively, in placebotreated subjects ( $p<0.001$ for both domains) [49]. In a subsequent study comprising 400 symptomatic SAR patients, Noonan et al. [50] confirmed these findings by demonstrating that treatment for 2 weeks with cetirizine $10 \mathrm{mg}$ resulted in significantly greater improvements in mean TSSC (-3.85) and RQLQ overall $(-1.42)$ scores compared with placebo $(-2.56, \mathrm{p}<0.01$; and -0.88 , $\mathrm{p}<$ 0.001 , respectively). All RQLQ domain scores were also improved to a significantly greater degree with cetirizine $10 \mathrm{mg}$, and the correlations between improvements of symptomatic relief and RQLQ overall score were moderate to strong and significant in cetirizine-treated patients at the end of treatment $(\mathrm{r}=0.49-0.68 ; \mathrm{p}<0.01)$ [50].

Studies in adolescents/children with SAR have investigated the effect of treatment with cetirizine 5-10 mg once daily for 2-4 weeks, on the change from baseline in symptom severity as the main efficacy measure [45-48]. Similarly to the studies in adults, all the studies in adolescents/ children demonstrated cetirizine to lead to significantly greater patient/guardian-assessed decreases in total and individual symptom severities compared with placebo. Similarly, physician-assessed global improvements or changes in symptoms have been shown to be significantly greater for cetirizine compared to placebo [45-48], with one study indicating physician-assessed relief from oral/ nasal or ocular itching to be significantly greater with cetirizine $10 \mathrm{mg}$ than with cetirizine $5 \mathrm{mg}$ or placebo [47]. The effect of cetirizine on health-related quality of life in children has also been investigated in one open-label noncomparative study of 572 children, using the Paediatric RQLQ (PRQLQ) [48]. This study demonstrated that treatment with cetirizine $10 \mathrm{mg}$ once daily for 4 weeks significantly improved the PRQLQ overall and all 5 domain scores and TSSCs (for sneezing, runny nose, itchy nose, itchy eyes, watery eyes, and postnasal drip) progressively over the course of treatment. Furthermore, there was a strong and significant correlation between the improvements in PRQLQ overall and TSSC scores after 2 weeks $(\mathrm{r}=0.39 ; \mathrm{p}<0.001)$ and after 4 weeks $(\mathrm{r}=0.48 ; \mathrm{p}<0.001)$.

Although there are comparatively fewer studies directly comparing the effects of cetirizine with placebo in patients suffering from PAR/PER, these have generally investigated the effects of treatment on symptom severity and quality of life. One study in adults investigated the effect of cetirizine $10 \mathrm{mg}$ and cetirizine $20 \mathrm{mg}$ once daily for 4 weeks and demonstrated that physician-assessed changes in symptom severity were significantly improved nearly twofold in both groups of cetirizine-treated patients (decreased by 43 and $42 \%$ with 10 and 20 mg cetiri- zine, respectively) compared to placebo (decreased by $23 \%$; $p<0.001$ vs. both the active groups) [51]. Assessment of the number of patients with $>50 \%$ improvement in symptom severity showed that a significantly greater number of patients treated with cetirizine $10 \mathrm{mg}$ (62\% patients) achieved this level of improvement compared with placebo treatment (34\% patients). Although a greater number of patients (49\%) treated with cetirizine $20 \mathrm{mg}$ also showed $>50 \%$ improvement in symptom severity, this did not reach a significant difference to placebo [51]. The dose-dependent effect of cetirizine 2.5, 5.0 or $10.0 \mathrm{mg}$ once daily for 2 weeks has been investigated in one large study involving 328 PAR children aged 6-12 years [52]. While assessment of days without any symptoms or only mild symptoms indicated only cetirizine $10 \mathrm{mg}$ to be significantly more effective than placebo in this regard (14.4\% for cetirizine $10 \mathrm{mg}$ vs. $7.1 \%$ for placebo; $\mathrm{p}=0.008$ ), assessment of days without severe symptoms indicated all doses of cetirizine to be significantly more effective than placebo $(80.7,79.3$ and $84.5 \%$ for cetirizine $2.5,5.0$ and $10.0 \mathrm{mg}$, respectively, vs. $70.0 \%$ for placebo; $\mathrm{p}<0.0$ for all). Bousquet et al. [53] have also demonstrated treatment with cetirizine $10 \mathrm{mg}$ once daily for 6 weeks to significantly increase the number of days without any symptoms or only mild symptoms compared with placebo ( $42 \%$ for cetirizine vs. $2.6 \%$ for placebo; $p=0.0001$ ) and to lead to significantly greater improvements in the quality of life from 1 week onwards, in adults with PAR $[53,54]$. The magnitude of improvement noted in symptom-free or mild symptom days suggests that cetirizine may be even more effective over longer treatment periods.

\section{Studies Comparing Cetirizine with Other SGAHs in $S A R$ and PAR/PER Patients}

The efficacy of therapeutic doses of cetirizine has been compared in several studies with that of therapeutic doses of other commonly employed and newer preparations of SGAHs in adolescent/adult patients with SAR [55-72] and adolescent/adult and paediatric patients with PAR/ PER [73-80]. The majority of these studies have compared the effects of the various antihistamines directly with that of cetirizine and/or placebo on the reduction of symptom severity scores, using different composites of the individual symptom scores as the main efficacy measure.

\section{Studies in SAR Patients}

Early studies compared the efficacy of astemizole [55], terfenadine [56] or ebastine [57] with cetirizine in symptomatic SAR adolescent/adult outpatients during the pol- 
len season. A comparison of the efficacy of once daily treatment for 2 weeks with astemizole $10 \mathrm{mg}$, cetirizine $5 \mathrm{mg}$, or cetirizine $10 \mathrm{mg}$ demonstrated that although all treatments significantly decreased total symptom severity compared to baseline, there was no significant difference between the treatments [55]. Despite the lack of difference in symptom severity by the end of treatment, a significantly greater number of patients treated with cetirizine $(65 \%)$ indicated satisfaction with their treatment compared with patients treated with astemizole $(51 \%$; $p<$ 0.05) [5]. Similarly, studies comparing the efficacy of therapeutic doses of terfenadine $60 \mathrm{mg}$ twice daily [56] or ebastine $10 \mathrm{mg}$ once daily [57] with cetirizine $10 \mathrm{mg}$ once daily for 2 weeks showed cetirizine to be equally efficacious as terfenadine and ebastine in improving the symptoms of rhinitis, as evaluated by both patients and investigators. In one randomized double-blind, double-dummy study Meltzer et al. [58] compared the effect of treatment with loratadine $10 \mathrm{mg}$, cetirizine $10 \mathrm{mg}$, or placebo, once daily, on 2 consecutive days to natural pollen exposure in a park during the pollen season in 279 adolescent and adult SAR patients. The authors evaluated primarily the effect of treatment on the change from baseline in the major symptom complex (MSC; a composite of individual scores for the major symptoms of runny nose, sniffles, itchy nose, nose blows, sneezes, and watery eyes) and total symptom complex (TSC; a composite of the MSC plus scores for itchy eyes or ears, itchy throat, cough, and postnasal drip) scores, and demonstrated that cetirizine produced significantly superior mean overall reductions than loratadine or placebo in both MSC [ -4.1 vs. -2.3 points change for cetirizine vs. loratadine after the first $24 \mathrm{~h}(\mathrm{p}<0.01)$, and $-7.5 \mathrm{vs}$. -6.2 points change at the study end $(\mathrm{p}<0.05)]$ and TSC $[-6.3$ vs. -3.8 points change for cetirizine vs. loratadine after the first $24 \mathrm{~h}(\mathrm{p}<0.01)$, and -11.9 vs. -10.1 points change at study end $(\mathrm{p}<0.05)$ ] scores over $24 \mathrm{~h}$ and by study end. Furthermore, cetirizine demonstrated a significantly faster onset of action $(<2 \mathrm{~h})$ and greater reductions in symptoms over $24 \mathrm{~h}$, as well as significantly better patient assessment of improved global efficacy compared with loratadine $(73.6 \%$ of patients for cetirizine vs. $56.5 \%$ of patients for loratadine; $\mathrm{p}<$ $0.05)$. In contrast, the effect of loratadine did not significantly alter either MSC or TSC scores compared with placebo [58]. Two studies investigating the effect of loratadine on allergen-induced symptoms of AR in 'pollenprimed' subjects in an environment exposure unit have confirmed the general finding for an overall lack of a significant difference between a single dose of loratadine $10 \mathrm{mg}$ and placebo in providing either clinically relevant or definitive symptom relief [59] or in significantly reducing mean TSC and MSC scores from baseline at the study end point [60]. A subsequent study conducted in the environment exposure unit did, however, manage to demonstrate significant differences in reduced mean baseline TSC and MSC scores between patients treated with loratadine $10 \mathrm{mg}$ and placebo [61]. Nevertheless, a comparison with cetirizine in all these studies demonstrated that a single dose of cetirizine $10 \mathrm{mg}$ was significantly more efficacious than loratadine $10 \mathrm{mg}$ and placebo in providing both symptom relief and reducing total symptom severity scores [59-61] and that these effects were prevalent over the entire course of the 28.5 -hour period investigated following administration of the first treatment dose [60, 61]. Similarly, comparison between single doses of fexofenadine $180 \mathrm{mg}$ and cetirizine $10 \mathrm{mg}$ in SAR patients 'primed' with pollen in the environment exposure unit have demonstrated cetirizine $10 \mathrm{mg}$ to be significantly superior to fexofenadine $180 \mathrm{mg}$ and placebo in reducing the symptoms of $\mathrm{AR}$ over the entire course of study period following administration of the initial dose $[62,63]$. In contrast, other studies have not been able to demonstrate any significant differences between fexofenadine $120 \mathrm{mg}$ or fexofenadine $180 \mathrm{mg}$ and cetirizine $10 \mathrm{mg}$ in the treatment of AR symptoms in patients exposed to pollen under experimental [64] or natural seasonal $[65,66]$ conditions, although all active treatments were significantly more effective than placebo. Similarly, several studies investigating the less commonly employed or newer preparations of $\mathrm{H}_{1}$ antihistamines in the treatment of symptoms in sensitized and symptomatic SAR patients during the grass/tree pollen season have not been able to show significant differences between therapeutic doses of cetirizine and mizolastine [67], emedastine [68], rupatadine [69], bilastine [70] or azelastine [71], although all active treatments were significantly effective in reducing specific total symptom severity scores from baseline or when compared with placebo. Azelastine has been administered as a nasal spray formulation and has produced conflicting data in two large multicentre comparative trials in the USA [71, 72]. While one study in 354 patients was unable to demonstrate any significant differences between cetirizine $10 \mathrm{mg}$ q.i.d. and azelastine 2 sprays/nostril b.i.d, in decreasing the total nasal symptom score (a composite of individual scores for the major symptoms of rhinorrhoea, sneezing, itchy nose, and nasal congestion) from baseline at the end of a 2-week treatment period (19.6 vs. $23.9 \%$ change from baseline for cetirizine and azelastine, respectively; $\mathrm{p}<0.0 .001$ for both active agents vs. baseline) [71], another study of similar design 
in 307 patients demonstrated azelastine to be significantly more effective than cetirizine in this respect ( 23 vs. $29.3 \%$ change from baseline for cetirizine and azelastine, respectively; $\mathrm{p}<0.001$ for both active agents vs. baseline and $\mathrm{p}=0.015$ for azelastine vs. cetirizine) [72]. Although both studies showed cetirizine and azelastine to improve the quality of life of patients significantly compared to baseline levels, the improvements were significantly greater for the azelastine-treated group (change from baseline RQLQ overall score $=1.11 / 1.13$ for cetirizine and $1.35 / 1.41$ for azelastine; $\mathrm{p}<0.001$ for both active agents vs. baseline and $\mathrm{p}<0.01 / 0.05$ for azelastine vs. cetirizine) $[71,72]$.

\section{Studies in PAR/PER Patients}

Comparatively fewer studies have investigated the effects of SGAHs in patients suffering from PAR/PER [7380]. Unlike the studies in SAR patients, these studies have often investigated the effect of these drugs over a period of 4 weeks or longer due to the more chronic nature of the symptoms. Two studies have investigated the effects of loratadine [73], ketotifen [74] and oxatomide [74] in paediatric patients, and demonstrated that all drugs significantly reduced the AR symptoms from baseline and versus placebo. Comparison of the effects of cetirizine, ketotifen and oxatamide additionally demonstrated cetirizine to produce significantly greater reductions from baseline levels in mean total symptom scores $(63.7 \%$ for cetirizine, $48.6 \%$ for ketotifen and $48.1 \%$ for oxatamide; $\mathrm{p}<0.05$ for cetirizine vs. ketotifen/ oxatamide) by the end of treatment [74]. Although all active drugs were also found to improve the health-related quality of life of the children, as indicated by smaller mean overall PRQLQ scores after 12 weeks' treatment, only the effects of cetirizine and oxatamide were significant compared with placebo (mean PRQLQ scores = 46.9 for placebo vs. 26.9 for cetirizine and 26.2 for oxatamide; $\mathrm{p}<0.05$ placebo vs. cetirizine/oxatamide) [74]. Assessment of the effect on eosinophils indicated cetirizine to significantly reduce nasal eosinophils from baseline levels [74]. Similarly, studies investigating the effects of terfenadine [75], ebastine [76], loratadine [77], rupatadine $[78,79]$, and bilastine [80] have demonstrated these agents to lead to significantly greater decreases in symptoms and symptom severity, compared to baseline levels or placebo, in adolescent/adult patients with PAR/ PER. While cetirizine exhibited significantly greater decreases in symptoms and symptom severity, compared to baseline or placebo [75-77], significant treatment differences in favour of cetirizine were also observed be- tween cetirizine- and ebastine-treated patients for mean changes in total symptom severity scores after 1 week of treatment and for the percentage of completely symptom-free patients after 4 weeks of treatment [76]. Besides improving symptoms of AR, cetirizine $10 \mathrm{mg}$ was similarly effective as loratadine $10 \mathrm{mg}$ in reducing $>20 \%$ nasal eosinophils in significantly greater number of patients compared with placebo [77], and similarly effective as rupatadine $10 \mathrm{mg}$ in significantly improving overall RQLQ scores compared with placebo, after 4 and 12 weeks of treatment [78].

\section{Studies Comparing Cetirizine with}

Non-Antihistamine Drugs

It is noteworthy that cetirizine has been used as an active comparator for several non-antihistamine therapies as well, investigated for efficacy in the management of patients with AR [81-84]. One study compared the effect of randomized, double-blind treatment for 1 year with either intranasal budesonide $400 \mu \mathrm{g}$ or oral cetirizine 10 $\mathrm{mg}$, on the relapse rates in PAR patients after treatment discontinuation [81]. The authors demonstrated that a significantly smaller number of patients treated with budesonide (38\%) had a relapse within the first month compared to patients treated with cetirizine $(56 \%$; $p<$ $0.05)$, with a non-significant difference in the median time to first relapse (62 vs. 20 days, respectively) [81]. Similarly, the effect of montelukast, a leukotriene receptor antagonist, has been compared with cetirizine in 2 studies $[82,83]$. One placebo-controlled study in children with PAR demonstrated that treatment with montelukast $4 \mathrm{mg}$ once daily or cetirizine $5 \mathrm{mg}$ once daily for 12 weeks resulted in significantly greater mean reductions from baseline in total symptom scores, overall PRQLQ scores, nasal airway resistance, and percentage eosinophils in nasal smears over the course of the study, compared with placebo [82]. Moreover, cetirizine was significantly superior to montelukast in decreasing total symptom scores by the end of treatment. Another trial in adult PAR patients treated with montelukast $10 \mathrm{mg}$ or cetirizine $10 \mathrm{mg}$ for 6 weeks demonstrated significantly greater mean changes from baseline in daytime nasal symptom scores after 4 weeks, but not after 6 weeks, with both active treatments compared with placebo [83]. The effect of a 2-year course of specific immunotherapy has also been compared with continuous or on-demand treatment with cetirizine $10 \mathrm{mg}$ once daily in patients with severe PER [35]. The authors demonstrated that immunotherapy and continuous cetirizine treatment were significantly more effective than on-demand cetirizine treatment, and signifi- 
cantly decreased ICAM-1 and eosinophil cationic protein to comparable levels by the end of treatment compared with baseline levels. Furthermore, at the end of treatment, $75 \%$ of patients in the immunotherapy group and $78 \%$ of patients in the continuous cetirizine-treatment group were free of rhinorrhoea, nasal obstruction, sneezing, hyposmia, sensation of ocular foreign body, and lacrimation, compared with $24 \%$ of patients in the cetirizine ondemand group [35]. More recently, it has been proposed that histamine $\mathrm{H}_{3}$ receptor antagonism may be complementary to the well-documented benefits of $\mathrm{H}_{1}$ receptor antagonism in $\mathrm{AR}$, and thus one preliminary study has compared the efficacies of two novel $\mathrm{H}_{1} / \mathrm{H}_{3}$ dual receptor antagonists (intranasal suspension of GSK1004723 and oral GSK835726) with cetirizine $10 \mathrm{mg}$ in 'primed' SAR patients exposed to allergen in an environmental allergen challenge chamber [84]. This study indicated that 10-, 50-, and 100-mg single doses and a 10-mg 3-day repeat dose of oral GSK835726 produced clinically significant attenuation of symptoms comparable to cetirizine $10 \mathrm{mg}$. While a 3-day repeat dose of intranasal GSK1004723 $1 \mathrm{mg}$, but not single doses of 0.22 or $1 \mathrm{mg}$, significantly attenuated symptoms from pretreatment levels, this effect was not as marked as that seen for oral GSK835726 or cetirizine $10 \mathrm{mg}$.

\section{Safety-Related Studies}

Although each clinical trial is usually designed to report drug-related adverse events, research focused on specific safety parameters is increasing. The lack of cardiotoxic potential with cetirizine use, a subject of concern with some of the first SGAHs, has been well established $[85,86]$. No deleterious effects on pregnant or lactating women have been reported with cetirizine. The Food and Drug Administration has classified cetirizine as a pregnancy category B drug, i.e. without known harm to an animal foetus and no human studies available. Of note is that some other widely used SGAHs, e.g. desloratadine and fexofenadine, are in category C, i.e. demonstrated harmful to an animal foetus and with unknown effects in humans [87]. Although research employing subjective assessments of the central nervous system effects of cetirizine has produced conflicting data, studies involving objective assessments, e.g. driving and psychomotor performance tests, have unanimously demonstrated that therapeutic doses of cetirizine do not generally produce more psychomotor impairment than placebo [88]. Similarly, the adverse effect profile of cetirizine has been shown to be comparable with that of astemizole, ebastine, fexofenadine, loratadine, mizolastine, or terfenadine [38]; with the adverse effects of cetirizine generally being of mild-to-moderate intensity. Importantly, the longest clinical trial with any antihistamine launched in the 20th century, the ETAC study, in children as young as 1824 months at randomization, demonstrated that continuous cetirizine treatment over 18 months had no adverse effects on neurological and behavioural events, nor on natural development milestones, e.g. no influence on height, body mass, gross and fine motor skills, speech and language skills, haematology and biochemistry tests. The proportion of treatment-emergent adverse events in the ETAC study, as described by the investigators, was similar between the cetirizine and placebo groups [89].

\section{Discussion and Conclusion}

There is a large body of evidence which demonstrates that cetirizine is a highly efficacious, fast-acting, well-tolerated, and quality-of-life-improving treatment for the management of paediatric, adolescent and adult patients suffering from moderate to severe AR. Indeed, one recent review of SGAHs has indicated that cetirizine is the most studied and one of the most potent antihistamines available, which may be appropriate for patients proven unresponsive to other antihistamines and for those with the severest symptoms who might benefit from antihistamine treatment of the highest potency that can be dosetitrated up to maximal intensity [90]. The evidence presented in the current review further demonstrates that despite being one of the first SGAHs to be developed over 2 decades ago, cetirizine is the most commonly used oral antihistamine worldwide and its use is currently recommended by virtually all evidence-based international treatment guidelines for AR [12]. Comparison of cetirizine with other SGAHs, old and new, has generally demonstrated cetirizine to have a more favourable pharmacological profile and to be at least equally or more effective than many of these agents in reducing the symptoms of $A R$ and improving the health-related quality of life in both SAR and PAR/PER patients. Apart from the findings for the pharmacological profiles and clinical efficacies of the different SGAHs, an interesting observation for the majority of the earlier studies and many of the more recent studies in SAR and PAR/PER patients has been that cetirizine was often employed as the main comparator active drug for the other SGAHs, irrespective of whether or not a placebo was used.
Zhang/Cheng/Hong 
Based on the evidence of the studies investigating the clinical efficacy of traditional and non-traditional pharmacotherapies in $\mathrm{AR}$, and the finding that cetirizine was commonly employed as an active comparator drug for other SGAHs, it is tempting to suggest that cetirizine may be a suitable benchmark/gold standard for the assessment of safety and efficacy of novel pharmacotherapies for AR.

\section{Acknowledgements}

The authors would like to thank UCB Farchim SA for financial support and Dr. Jagdish Devalia for assistance with the preparation and editing of this article.

\section{Disclosure Statement}

The authors declare that they have no conflict of interest.

\section{References}

1 Schatz M: A survey of the burden of allergic rhinitis in the USA. Allergy 2007;62(suppl 85):9-16.

2 Canonica GW, Bousquet J, Mullol J, et al: A survey of the burden of allergic rhinitis in Europe. Allergy 2007;62(suppl 85):17-25.

3 Schoenwetter WF, Dupclay L, Appajosyula S, et al: Economic impact and quality of life burden of allergic rhinitis. Curr Med Res Opin 2004;20:305-317.

4 Meltzer EO, Nathan R, Derebery J, et al: Sleep, quality of life, and productivity impact of nasal symptoms in the United States: findings from the Burden of Rhinitis in America survey. Allergy Asthma Proc 2009;30:244-254.

5 Nathan RA: The burden of allergic rhinitis. Allergy Asthma Proc 2007;28:3-9.

6 Blaiss MS: Pediatric allergic rhinitis: physical and mental complications. Allergy Asthma Proc 2007;29:1-6.

7 Meltzer EO, Blaiss MS, Derebery MJ, et al: Burden of allergic rhinitis: results from the Pediatric Allergies in America survey. J Allergy Clin Immunol 2009;124(suppl): S43-S70.

8 Katelaris $\mathrm{CH}$, Lee BW, Potter PC, et al: Prevalence and diversity of allergic rhinitis in regions of the world beyond Europe and North America. Clin Exp Allergy 2012;42:186-207.

\$ Zhang L, Han D, Huang D, Wu Y, Dong Z, et al: Prevalence of self-reported allergic rhinitis in eleven major cities in China. Int Arch Allergy Immunol 2009;149:47-57.

10 Mösges R, Klimek L: Today's allergic rhinitis patients are different: new factors that may play a role. Allergy 2007:62:969-975.

11 Barnes C, Dinakar C, Reddy M, Portnoy J: Frequency of fungi in homes of pediatric allergy patients. Allergy Clin Immunol Int J World Allergy Org 2006;18:197-202.

$\$ 12$ Bousquet J, Khaltaev N, Cruz AA, et al: Allergic Rhinitis and Its Impact on Asthma (ARIA) 2008 update [in collaboration with the World Health Organization, GA(2)LEN and AllerGen]. Allergy 2008;63(suppl 86):8-160.

13 Wallace DV, Dykewicz MS, Bernstein DI, et al: The diagnosis and management of rhinitis: an updated practice parameter. J Allergy Clin Immunol 2008;122(suppl):S1-S84.

-14 Scadding GK, Durham SR, Mirakian R, et al: BSACI guidelines for the management of al- lergic and non-allergic rhinitis. Clin Exp Allergy 2008;38:19-42.

15 Emanuel MB: Histamine and antiallergic antihistamines: a history of their discover
Clin Exp Allergy 1999;29(suppl 3):1-11.

$\rightarrow 16$ Simons FE, Simons KJ: Histamine and $\mathrm{H}_{1}$ antihistamines: celebrating a century of progress. J Allergy Clin Immunol 2011;128:11391150.

17 Church MK, Maurer M, Simons FE, et al: Risk of first-generation $\mathrm{H}_{1}$ antihistamines: a GA(2) LEN position paper. Allergy 2010;65:459466.

18 Schad CA, Skoner DP: Antihistamines in the pediatric population: achieving optimal outcomes when treating seasonal allergic rhinitis and chronic urticaria. Allergy Asthma Proc 2008;29:7-13.

19 Taglialatela M, Castaldo P, Pannaccione A, et al: Cardiac ion channels and antihistamines: possible mechanisms of cardiotoxicity. Clin Exp Allergy 1999;29(suppl 3):182-189.

20 Tillement J-P, Testa B, Brée F: Compared pharmacological characteristics in humans of racemic cetirizine and levocetirizine, two histamine $\mathrm{H}_{1}$-receptor antagonists. Biochem Pharmacol 2003;66:1123-1126.

21 Pagliara A, Testa B, Carrupt PA, et al: Molecular properties and pharmacokinetic behavior of cetirizine, a zwitterionic $\mathrm{H}_{1}$-receptor antagonist. J Med Chem 1998;41:853-863.

22 Tillement JP: The advantages for an $\mathrm{H}_{1}$ antihistamine of a low volume of distribution. Allergy 2000;55(suppl 60):17-21.

23 Wood SG, John BA, Chasseaud LF, et al: The metabolism and pharmacokinetics of ${ }^{14} \mathrm{C}$-cetirizine in humans. Ann Allergy 1987;59:31-34.

24 Greisner WA 3rd: Onset of action for the relief of allergic rhinitis symptoms with secondgeneration antihistamines. Allergy Asthma Proc 2004;25:81-83.

25 Horsmans Y, Desager JP, Hulhoven R, et al: Single-dose pharmacokinetics of cetirizine in patients with chronic liver disease. J Clin Pharmacol 1993;33:929-932.

26 Boobis A, Watelet JB, Whomsley R, et al: Drug interactions. Drug Metab Rev 2009;41: 486-527.

27 Lefebvre RA, Rosseel MT, Bernheim J: Single dose pharmacokinetics of cetirizine in young and elderly volunteers. Int J Clin Pharmacol Res 1988;8:463-470.

28 Gillard M, Christophe B, Wels B, et al: $\mathrm{H}_{1}$ antagonists: receptor affinity versus selectivity. Inflamm Res 2003;52(suppl 1):S49-S50.

29 Fadel R, Herpin-Richard N, Rihoux JP, et al: Inhibitory effect of cetirizine ${ }^{2} \mathrm{HCl}$ on eosinophil migration in vivo. Clin Allergy 1987;17: 373-379.

30 Watson WT, Simons KJ, Chen XY, et al: Cetirizine: a pharmacokinetic and pharmacodynamic evaluation in children with seasonal allergic rhinitis. J Allergy Clin Immunol 1989; 84:457-464.

31 Ciprandi G, Tosca M, Ricca V, et al: Cetirizine treatment of rhinitis in children with pollen allergy: evidence of its antiallergic activity. Clin Exp Allergy 1997;27:1160-1166.

32 Ciprandi G, Tosca MA, Milanese M, et al: Cetirizine reduces cytokines and inflammatory cells in children with perennial allergic rhinitis. Eur Ann Allergy Clin Immunol 2004;36: 237-240.

33 Fasce L, Ciprandi G, Pronzato C, et al: Cetirizine reduces ICAM-I on epithelial cells during nasal minimal persistent inflammation in asymptomatic children with mite-allergic asthma. Int Arch Allergy Immunol 1996;109: 272-276.

34 Ciprandi G, Passalacqua G, Mincarini M, et al: Continuous versus on demand treatment with cetirizine for allergic rhinitis. Ann Allergy Asthma Immunol 1997;79:507-511.

35 Lauriello M, Muzi P, Di Rienzo L, et al: A twoyear course of specific immunotherapy or of continuous antihistamine treatment reverses eosinophilic inflammation in severe persistent allergic rhinitis. Acta Otorhinolaryngol Ital 2005;25:284-291.

36 Shirasaki H, Watanabe K, Kanaizumi E, et al: Effects of cetirizine on substance $P$ release in patients with perennial allergic rhinitis. Ann Otol Rhinol Laryngol 2004;113:941-945.

37 Grant JA, Danielson L, Rihoux JP, et al: A double-blind, single-dose, crossover comparison of cetirizine, ebastine, epinastine, fexofenadine, terfenadine, and loratadine versus placebo: suppression of histamine-induced wheal and flare response for $24 \mathrm{~h}$ in healthy male subjects. Allergy 1999;54:700-707. 
38 Curran MP, Scott LJ, Perry CM: Cetirizine: a review of its use in allergic disorders. Drugs 2004;64:523-561.

-39 Takahashi H, Ishida-Yamamoto A, Iizuka H: Effects of bepotastine, cetirizine, fexofenadine, and olopatadine on histamine-induced wheal-and flare response, sedation, and psychomotor performance. Clin Exp Dermatol 2004;29:526-532.

40 Church MK: Comparative inhibition by bilastine and cetirizine of histamine-induced wheal and flare responses in humans. Inflamm Res 2011;60:1107-1112.

41 Purohit A, Melac M, Pauli G, et al: Comparative activity of cetirizine and desloratadine on histamine-induced wheal-and-flare responses during $24 \mathrm{~h}$. Ann Allergy Asthma Immunol 2004;92:635-640.

42 Devalia JL, De Vos C, Hanotte F, et al: A randomized, double-blind, crossover comparison among cetirizine, levocetirizine, and UCB 28557 on histamine-induced cutaneous responses in healthy adult volunteers. Allergy 2001;56:50-57.

43 Panayotopoulos SM, Panayotopoulou ES: Efficacy of cetirizine in the treatment of seasonal allergic rhinoconjunctivitis. Ann Allergy 1990;65:146-168.

-44 Falliers CJ, Brandon ML, Buchman E, et al: Double-blind comparison of cetirizine and placebo in the treatment of seasonal rhinitis. Ann Allergy 1991;66:257-262.

45 Allegra L, Paupe J, Wieseman HG, et al: Cetirizine for seasonal allergic rhinitis in children aged 2-6 years. A double-blind comparison with placebo. Pediatr Allergy Immunol 1993;4 157-161.

46 Masi M, Candiani R, van de Venne H: A placebo-controlled trial of cetirizine in seasonal allergic rhino-conjunctivitis in children aged 6 to 12 years. Pediatr Allergy Immunol 1993; 4(suppl 4):47-52.

-47 Pearlman DS, Lumry WR, Winder JA, et al: Once-daily cetirizine effective in the treatment of seasonal allergic rhinitis in children aged 6 to 11 years: a randomized, doubleblind, placebo-controlled study. Clin Pediatr (Phila) 1997;36:209-215.

48 Gillman SA, Blatter M, Condemi JJ, et al: The health-related quality of life effects of oncedaily cetirizine $\mathrm{HCl}$ syrup in children with seasonal allergic rhinitis. Clin Pediatr (Phila) 2002;41:687-696.

49 Murray JJ, Nathan RA, Bronsky EA, et al: Comprehensive evaluation of cetirizine in the management of seasonal allergic rhinitis: impact on symptoms, quality of life, productivity, and activity impairment. Allergy Asthma Proc 2002;23:391-398.

50 Noonan MJ, Raphael GD, Nayak A, et al: The health-related quality of life effects of oncedaily cetirizine $\mathrm{HCl}$ in patients with seasonal allergic rhinitis: a randomized double-blind, placebo-controlled trial. Clin Exp Allergy 2003;33:351-358

-51 Mansmann HC Jr, Altman RA, Berman BA, et al: Efficacy and safety of cetirizine therapy in perennial allergic rhinitis. Ann Allergy 1992;68:348-353.

52 Jobst S, van den Wijngaart W, Schubert A, et al: Assessment of the efficacy and safety of three dose levels of cetirizine given once daily in children with perennial allergic rhinitis. $\mathrm{Al}$ lergy 1994;49:598-604.

53 Bousquet J, Duchateau J, Pignat JC, et al: Improvement of quality of life by treatment with cetirizine in patients with perennial allergic rhinitis as determined by a French version of the SF-36 questionnaire. J Allergy Clin Immunol 1996;98:309-316.

54 Burtin B, Duchateau J, Pignat JC, et al: Further improvement of quality of life by cetirizine in perennial allergic rhinitis as a function of treatment duration. J Investig Allergol Clin Immunol 2000;10:66-70.

55 Berkowitz RB, Dockhom R, Lockey R, et al: Comparison of efficacy, safety, and skin test inhibition of cetirizine and astemizole. Ann Allergy Asthma Immunol 1996;76:363-368.

56 Lockey RF, Widlitz MD, Mitchell DQ, et al: Comparative study of cetirizine and terfenadine versus placebo in the symptomatic management of seasonal allergic rhinitis. Ann Allergy Asthma Immunol 1996;76:448-454.

57 Gehanno P, Bremard-Oury C, Zeisser P: Comparison of ebastine to cetirizine in seasonal allergic rhinitis in adults. Ann Allergy Asthma Immunol 1996;76:507-512.

58 Meltzer EO, Weiler JM, Widlitz MD: Comparative outdoor study of the efficacy, onset and duration of action, and safety of cetirizine, loratadine, and placebo for seasonal allergic rhinitis. J Allergy Clin Immunol 1996;97:617-626.

59 Day JH, Briscoe MP, Clark RH, et al: Onset of action and efficacy of terfenadine, astemizole, cetirizine, and loratadine for the relief of symptoms of allergic rhinitis. Ann Allergy Asthma Immunol 1997;79:163-172.

60 Day JH, Briscoe M, Widlitz MD: Cetirizine, loratadine, or placebo in subjects with seasonal allergic rhinitis: effects after controlled ragweed pollen challenge in an environmental exposure unit. J Allergy Clin Immunol 1998; 101:638-645.

61 Day JH, Briscoe M, Rafeiro E, et al: Comparative onset of action and symptom relief with cetirizine, loratadine, or placebo in an environmental exposure unit in subjects with seasonal allergic rhinitis: confirmation of a test system. Ann Allergy Asthma Immunol 2001; 87:474-481.

62 Day JH, Briscoe MP, Rafeiro E, et al: Randomized double-blind comparison of cetirizine and fexofenadine after pollen challenge in the environmental exposure unit: duration of effect in subjects with seasonal allergic rhinitis. Allergy Asthma Proc 2004;25:59-68.

63 Day JH, Briscoe MP, Rafeiro E, et al: Comparative efficacy of cetirizine and fexofenadine for seasonal allergic rhinitis, $5-12 \mathrm{~h}$ postdose, in the environmental exposure unit. $\mathrm{Al}$ lergy Asthma Proc 2005;26:275-282.

64 Horak F, Stübner P, Zieglmayer R, et al: Controlled comparison of the efficacy and safety of cetirizine $10 \mathrm{mg}$ o.d. and fexofenadine 120 $\mathrm{mg}$ o.d. in reducing symptoms of seasonal allergic rhinitis. Int Arch Allergy Immunol 2001;125:73-79.

65 Howarth PH, Stem MA, Roi L, et al: Doubleblind, placebo controlled study comparing the efficacy and safety of fexofenadine hydrochloride (120 and $180 \mathrm{mg}$ once daily) and cetirizine in seasonal allergic rhinitis. J Allergy Clin Immunol 1999; 104:927-933.

66 Hampel F, Ratner P, Mansfield L, et al: Fexofenadine hydrochloride, $180 \mathrm{mg}$, exhibits equivalent efficacy to cetirizine, $10 \mathrm{mg}$, with less drowsiness in patients with moderate-tosevere seasonal allergic rhinitis. Ann Allergy Asthma Immunol 2003;91:354-361.

67 Sabbah A, Daele J, Wade AG, et al: Comparison of the efficacy, safety, and onset of action of mizolastine, cetirizine, and placebo in the management of seasonal allergic rhinoconjunctivitis. MIZOCET Study Group. Ann Allergy Asthma Immunol 1999;83:319325.

68 Horak F, Stübner P, Zieglmayer R, et al: Clinical study of the therapeutic efficacy and safety of emedastine difumarate versus cetirizine in the treatment of seasonal allergic rhinitis. Arzneimittelforschung 2004;54:666-672.

69 Martínez-Cócera C, De Molina M, MartíGuadaño E, et al: Rupatadine $10 \mathrm{mg}$ and cetirizine $10 \mathrm{mg}$ in seasonal allergic rhinitis: a randomised, double-blind parallel study. J Investig Allergol Clin Immunol 2005; 15:2229.

70 Kuna P, Bachert C, Nowacki Z, et al: Efficacy and safety of bilastine $20 \mathrm{mg}$ compared with cetirizine $10 \mathrm{mg}$ and placebo for the symptomatic treatment of seasonal allergic rhinitis: a randomized, double-blind, parallelgroup study. Clin Exp Allergy 2009;39:13381347.

71 Berger W, Hampel F Jr, Bernstein J, et al: Impact of azelastine nasal spray on symptoms and quality of life compared with cetirizine oral tablets in patients with seasonal allergic rhinitis. Ann Allergy Asthma Immunol 2006; 97:375-381.

72 Corren J, Storms W, Bernstein J, et al: Effectiveness of azelastine nasal spray compared with oral cetirizine in patients with seasonal allergic rhinitis. Clin Ther 2005;27:543-553.

73 Sienra-Monge JJ, Gazca-Aguilar A, Del RioNavarro B: Double-blind comparison of cetirizine and loratadine in children ages 2 to 6 years with perennial allergic rhinitis. Am J Ther 1999;6:149-155.

74 Lai DS, Lue KH, Hsieh JC, et al: The comparison of the efficacy and safety of cetirizine, oxatomide, ketotifen, and a placebo for the treatment of childhood perennial allergic rhinitis. Ann Allergy Asthma Immunol 2002;89:589598.

75 Renton R, Fidler C, Rosenberg R: Multicenter, crossover study of the efficacy and tolerability of terfenadine, $120 \mathrm{mg}$, versus cetinzine, 10 $\mathrm{mg}$, in perennial allergic rhinitis. Ann Allergy 1991;67:416-420. 
76 Murris-Espin M, Melac M, Charpentier JC, et al: Comparison of efficacy and safety of cetirizine and ebastine in patients with perennial allergic rhinitis. Ann Allergy Asthma Immunol 1998;80:399-403.

77 Nunes C, Ladeira S: Double-blind study of cetirizine and loratadine versus placebo in patients with allergic rhinitis. J Investig Allergo Clin Immunol 2000;10:20-23.

78 Fantin S, Maspero J, Bisbal C, et al: A 12-week placebo-controlled study of rupatadine $10 \mathrm{mg}$ once daily compared with cetirizine $10 \mathrm{mg}$ once daily, in the treatment of persistent allergic rhinitis. Allergy 2008;63:924-931.

79 Marmouz F, Giralt J, Izquierdo I: Morning and evening efficacy evaluation of rupatadine (10 and $20 \mathrm{mg}$ ), compared with cetirizine 10 $\mathrm{mg}$ in perennial allergic rhinitis: a randomized, double-blind, placebo-controlled trial. J Asthma Allergy 2011;4:27-35.

80 Sastre J, Mullol J, Valero A, et al: Efficacy and safety of bilastine $20 \mathrm{mg}$ compared with cetirizine $10 \mathrm{mg}$ and placebo in the treatment of perennial allergic rhinitis. Curr Med Res Opin 2012;28:121-130.

81 Rinne J, Simola M, Malmberg H, et al: Early treatment of perennial rhinitis with budesonide or cetirizine and its effect on long-term outcome. J Allergy Clin Immunol 2002;109:426-432.
82 Chen ST, Lu KH, Sun HL, Chang WT, Lue $\mathrm{KH}$, Chou MC: Randomized placebo-controlled trial comparing montelukast and cetirizine for treating perennial allergic rhinitis in children aged 2-6 yr. Pediatr Allergy Immunol 2006;17:49-54.

83 Philip G, Williams-Herman D, Patel P, Weinstein SF, Alon A, Gilles L, Tozzi CA, Dass SB, Reiss TF: Efficacy of montelukast for treating perennial allergic rhinitis. Allergy Asthma Proc 2007;28:296-304.

84 Daley-Yates P, Ambery C, Sweeney L, et al: The efficacy and tolerability of two novel $\mathrm{H}_{1} /$ $\mathrm{H}_{3}$ receptor antagonists in seasonal allergic rhinitis. Int Arch Allergy Immunol 2012;158: 84-98.

85 Yap YG, Camm AJ: Potential cardiac toxicity of $\mathrm{H}_{1}$-antihistamines.Clin Allergy Immunol 2002;17:389-419.

86 Davie C, Pierre-Valentin J, Pollard C, et al: Comparative pharmacology of guinea pig cardiac myocyte and cloned hERG $(\mathrm{I}(\mathrm{Kr}))$ channel. J Cardiovasc Electrophysiol 2004;15: 1302-1309.
87 Yanai K, Rogala B, Chugh K, et al: Safety considerations in the management of allergic diseases: focus on antihistamines. Curr Med Res Opin 2012;28:623-642.

88 Theunissen EL, Vermeeren A, Ramaekers JG: Repeated-dose effects of mequitazine, cetirizine and dexchlorpheniramine on driving and psychomotor performance. $\mathrm{Br} \mathrm{J}$ Clin Pharmacol 2006;61:79-86.

89 Simons FE: Prospective, long-term safety evaluation of the $\mathrm{H}_{1}$-receptor antagonist cetirizine in very young children with atopic dermatitis. ETAC Study Group. Early Treatment of the Atopic Child. J Allergy Clin Immunol 1999;104:433-440.

-90 Golightly LK, Greos LS: Second-generation antihistamines: actions and efficacy in the management of allergic disorders. Drugs 2005;65:341-384

91 Gillman S, Gillard M, Strolin Benedetti M: The concept of receptor occupancy to predict clinical efficacy: a comparison of second generation $\mathrm{H}_{1}$ antihistamines. Allergy Asthma Proc 2009;30:366-376.

92 Chu NN, Chen WL, Xu HR, Li XN: Pharmacokinetics of orally administered single-and multiple-dose olopatadine in healthy Chinese subjects: an open-label study. Clin Drug Investig 2009;29:451-457. 